\title{
ENCOURAGEMENT OF FARM DRAINAGE IN NORTHLAND
}

\author{
By Professor A. W. Hudson, Massey Agricultural \\ College, Palmerston North.
}

Mr Scott has told you something of the machines which are available for digging tile trenches, $\mathrm{Mr}$ Bowler has given you an outline of how Massey College is endeavouring to meet the demand for farm drainage in the Manawatu, and $\mathrm{Mr}$ Banfield has dealt with surface drainage of land with little or no fall and where water cannot flow freely from under-drains.

No doubt you are wondering how some of the machines and methods described may be used in Northland and the extent to which the cost of the more expensive forms of land drainage may be recouped.

Before discussing these points I should like to tell you something of what is being done in England to encourage land drainage. Mr M. W. Cross, Lecturer in Farm Machinery at Massey College, has just returned from a visit to England, where he investigated drainage work and has kindly provided me with up-to-date information concerning it.

A Land Drainage Division of the Ministry of Agriculture-has-large-numbers of machines which carry out drainage work under contract for farmers. The connection between the Drainage Division and the farmer is through county committees. Essex, to quote one county of $720,000 *$ acres of agricultural land as an example, has 26 Roteho tile-trench diggers, 23 dragline excavators, 12 mole draining tractors, and 8 bulldozers available from the Ministry. Ten vans transport Roteho crews to their work on farms and motorcycles are provided, for dragline excavator operators. The county is divided into 8 drainage districts each-of which has a drainage officer. All come under the control of a chief drainage officer and-assistant at Chelmsford. Here a repair depot is maintained at which spare Rotehos are kept for quick replace-

*Note: An idea of the area represented by 720,000 facres will be gained from the fact that Whangarei and Hobson Counties together cover about 908,000 acres. 
ment and from which 6 fitters with workshop vans are continually servicing the machines in the field.

The organisation of the supply of machines and the servicing of them is outstanding. Unfortunately, however, the planning of drainage systems and their installation leave much to be desired due to an inadequacy of trained and experienced experts.' The drainage officers are concerned mainly with inspection and approval of projected schemes for which applications for subsidies have been lodged. Subsidies are granted on all approved schemes up to half their cost. Rates of hire for machines are moderate and designed to cover costs only.

Though the idea of subsidies may appeal to some, my own opinion is that any form of land improvement which will earn such handsome dividends as drainage is capable of doing does not need to be subsidised.

Costs of drain tiles and drain digging, in common with most other costs, have risen steeply in recent years. In New Zealand mole draining may cost from $30 /$ to several pounds per acre, depending on whether the farmer does his own drainage and whether relatively large numbers of tiles must be used to provide the necessary outfalls. Where mole draining is possible and effective there can be no doubt concerning its economic worth. The "economic attractiveness of tile draining is not so apparent until it is viewed as a long-term investment. It is then obvious that it is not so much a question of whether it pays or not, but rather one of raising money, to invest in what in most cases must be a highly lucrative practice if properly carried out and if full advantage is taken of the benefits it brings.

Twenty-five years is a- short life to expect from a well-installed and well cared for tile system-a very short life. Let us consider by way of example of a tile drainage scheme the unusually large cost of $£ 50$ per acre. If this is raised under a 25-year table mortgage scheme at $4 \frac{1}{8}$ per cent., an annual repayment of principal and -interest of $£ 35 \mathrm{~s}$. Would be entailed. In terms of butterfat this would mean $261 \mathrm{~b}$. at $2 \mathrm{~s}$. $6 \mathrm{~d}$. per $\mathrm{lb}$. Suffice it to say that it would be strange indeed if land in need of draining so intensively as to cost $£ 50$ per acre would not give a greater increase than $261 \mathrm{~b}$. of butterfat per acre. It is more than likely that such wet land could not be developed satisfactorily without drainage and the further advan- 
tages to be obtained from the use of fertilisers and improved, grasses and clovers could not be exploited. Most installations will cost much less than the amount used by way of example.

I should like now to speak about some of the factors which influence cost and the farmer's ability to have drain systems installed. First let me discuss the tile position. Last May 3in. and 4in. tiles were selling in Whangarei at about $92 \mathrm{~s}$. and $125 \mathrm{~s}$. per 100 respectively. They were railed 540 miles from Plimmerton, the main cost item being:

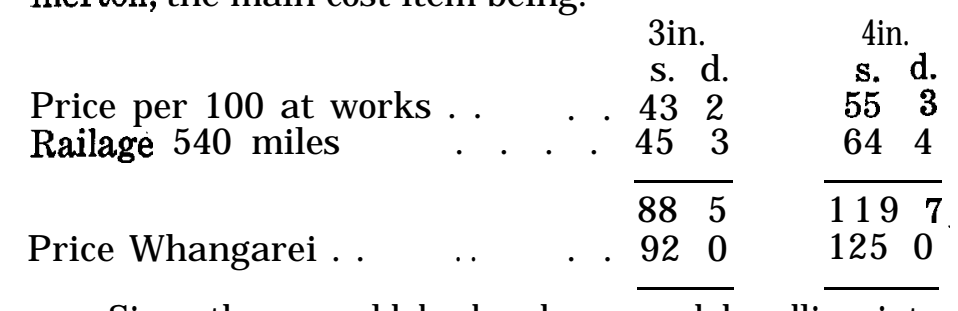

Since there would be breakages and handling into store, the difference between the price charged at Whangarei and the landed price is not unreasonable.

It is absurd, however, that tiles should be brought 540 miles when they are, being manufactured at New Lynn and could be manufactured in North Auckland. At the time the above tiles were being sold, 4in. tiles were on sale at New Lynn at 50s. per 100 . New Lynn is 121 miles from Whangarei and the railage per 100 4 in. tiles would cost $14 \mathrm{~s}$. $5 \mathrm{~d}$. Had these New Lynn tiles been procurable in Whangarei, they should have. sold for about $65 \mathrm{~s}$. to $70 \mathrm{~s}$. per 100 . If manufactured in-Whangarei-itself- their-cost-would-have-been-about50 s. ex works.

It had been my intention to urge Northland farmers to set up their own tile manufacturing plant, but I have been assured! by Mr Vose, Director of N.Z. Pottery and Ceramic Research Association, that the Amalgamated Brick \& Pipe Co. of Auckland has recently installed new equipment in its Kamo works and will shortly be turning out field tiles in considerable quantities. I would anticipate that local demand may be met for a short time by a supply from this source, but feel sure that with the increased supply of, suitable machines for digging tile trenches and a better appreciation of the value of drainage, the inevitable growth in the use of tile drainage will be such that production at some place north of Kamo may be highly desirable.

A second. factor affecting the installation of tile 
drains is that of labour supply. The art of hand digging tile drains is practically lost, and rightly so in an age dominated by "machines. Since the more efficient types of land drainage machinery are relatively costly, the farmer must rely to an increasing extent on having drainage carried: out by contractors who specialise in such work. The main difficulty, however, is that the tile draining contractor must be a much more skilled man than the man who ploughs, discs, or bulldozes the surface of the land, and few are prepared to go to the expense and trouble to fit themselves to be able to carry out the necessary surveying and planning associated with the proper use of tile drainage machinery. The operation of the machines is the easiest aspect of such-a contractor's activities. If he is to be a successful and self-contained contractor, he must be a versatile individual. I should like to outline some of the qualifications such a man should be equipped with.

1. By examining the soil he should be able to form a sound judgment as to the type of drainagemole, tile, open ditches, or shallow surface drainsbest suited to the conditions.

2. He should be able to determine the source of the water responsible for the wetness.

3. His plan based! on such determinations should be both efficient and as economical as possible.

4. To ensure efficiency and economy, his knowledge of the likely influence of drain positions, spacing and depth for a particular set of conditions must be something better than a mere guess.

5. He must be able to take levels quickly and accurately and where necessary carry out contour surveys.

6. He should be able to take a farm-or even a group of farms-as a drainage unit, plan a scheme, estimate cost, and advise the farmer the best order of procedure which, although following piecemeal execution, must conform to a complete and predetermined plan and fit into the general management of the farm.

7. He must know his soils ; which ones are best drained at one time of the year and which at another time, so that the work of his team can be planned to 
best advantage, and, above all, he must be a "big" enough man to admit that at times he must experiment with certain procedures on unusual soils before deciding definitely on a plan of action.

The above are only some of the things the drainage expert should know or be able to do. In short he should have a knowledge of soils and their agricultural use and be in addition a specialised type of civil engineer.

The criticism here could well be that such a combination of qualifications is idealistic and so rare as not likely to be found in conjunction with the inclination and financial ability to undertake contract work in farm drainage. I agree with the soundness of such criticism and propose later to offer suggestions as to how drainage experts may be trained.

In the meantime I should like to discuss possible alternative ways in which farm drainage units could be established and used under trained specialists.

1. A drainage specialist could be appointed to run a section of a well-established contracting business where workshop facilities for maintenance of plant are already available and! where drainage equipment would be an addition to existing plant. The drainage expert would require to have an interest in the business to ensure continuity of service sufficient to justify a period of training.

2. A drainage expert could be employed by a catchment board, county council, dairy company, or a group-of -farmers;-and-work-on-a-bonus-systemT profit sharing basis under bond to remain with the organisation sufficiently long to justify the expense of training.

3. As an alternative to (2) a dairy company or group of farmers, might with suitable safeguards consider financing promising young men into a course of training and the purchase of plant.

The above suggestions provide in the main for private enterprise to take full responsibility for the organisation and performance of the task of farm drainage:

Additional suggestions involving some measure of State assistance are as follows:

4. A Government Department could offer bursaries for the training of suitable candidates who, 
subject to satisfactory progress during their training, could be financed into the purchase of equipment on suitable terms.

5. A Government Department could take over full responsibility for the training and employment of drainage experts who would survey and plan drainage projects and prepare plans of completed schemes at cost. The experts would work in conjunction with approved contractors who could be given a short course of training sufficient only to enable them to follow on and install schemes planned and laid out by the experts. So that contractors would not be left high and dry on occasions, a team of experts capable of serving the needs of approved contractors at all times would have to be maintained by the Government Department. (Such a scheme is in operation, but on a very restricted scale.)

6. A Government Department could provide the whole service and carry out work at cost. There is a precedent for this in the activities of the Ministry of Works in surveying, planning, and carrying out the construction of borderdike farm irrigation schemes in Canterbury.

'7. Massey Agricultural College could! extend its drainage service to cover the whole of the North Island. Such an extension would be possible only if the College Council agreed and if the Government or a body such as Federated Farmers would guarantee the necessary funds for development. The existing service costs the taxpayer nothing, as it is selfsupporting, but it cannot develop rapidly without financial backing.

\section{THE DRAINAGE UNIT}

Mr Bowler has described to you a drainage unit which has been developed over 7 years and which is capable of coping with most of the problems in farm drainage.

Though the combination of the rotary-wheel type of digger and the hydraulically operated bucket excavator seems to be ideal, either can operate alone, the latter being capable of digging under a greater variety of conditions but at a much slower rate than the former. 
The present costs of new machines and equipment are approximately as follows:-

Roteho (Rotary wheel trench digger) . $\underset{2400}{\mathfrak{f}}$

Transporter for Roteho . . . . 500

Truck (I-wheel drive) for stores and equip-

ment, to haul transporter, 'and backfill

trenches

Land Rover (for personal and light stores,

etc.). . . . 1030

Car for drainage expert . . . 800

Surveying levels and equipment . . 380

'Boning rods, tools, etc. . . . . 150

Hydraulically operated bucket excavator .1250

Land Rover to haul excavator and transport

operator (using farmers' tractors)

or (Tractor to operate, haul excavator, and

(backfill trenches plus . . . 700)

(Van to transport operator or assistant 750 )

Car for additional expert . . . 800

Surveying equipment . . . . 80

Boning rods, tools, etc. . . . . 40

Allowance should be made also for a store and workshop in which to carry out maintenance work not done in the field.

The-hydraulically-operated--bucket excavator-andassociated equipment would cost about $£ 3500$ when farmers' tractors are used and $\$ 3920$ when a special tractor is used to haul and operate the excavator and backfill trenches.

A difficulty associated with a fast-cutting machine such as the Roteho is that at least 3 men are required in addition to the machine crew to place tiles in the trenches and to make junctions and outfalls. (This assumes that the tiles are laid on the lines before work commences). The 3 men referred to are difficult to arrange for on smaller farms even where there is good co=operation -between neighbours. The contractor cannot afford to employ these extra men unless he has alternative work for them during wet weather and when breakdowns occur.

The 'slower digging of the bucket excavator is 
compensated for to the extent that once the tiles are laid on the line only 2 men are required, one to operate the excavator and the other to check depth or grade, prepare the bottom, and lay the tiles.

The above provides a general picture of the requirements in terms of personnel and equipment for an individual drainage unit. There remains the important problem of how to train the people I have referred to as drainage experts. It is probable that money is more easily wasted on improperly sited and badly installed drains than on any other farm operation. Training of drainage experts is the only way to obviate this waste.

Earlier reference was made to the possibility of Government bursaries being made available to suitable trainees or that organisations directly interested in increasing farm production might finance the training and equipping of suitable men. The following suggestions are offered concerning the types of trainees and training.

1. The best type of trainee is a graduate in agriculture or a young man who has taken the diploma. in agriculture at one of the agricultural colleges. Alternatively, intelligent and energetic young farm workers whose financial position renders the acquisition of farms of their own a doubtful and indefinite prospect would be likely material.

2. Training should take the form of lectures, demonstrations, and practice in all phases of work from inspection, surveying, and planning to the actual operation and maintenance of machines and the laying of tiles. Administration and costing would be important subjects included in the training. Such training can be provided only by a service which is in active operation on a strictly business basis,

3. The only organisation equipped to carry out such training is Massey Agricultural College and .its Drainage Extension Service.

4. The period of training should be from 6 to 9 months, depending on whether the trainee intends to operate with the bucket excavator type of machine only or with both types.

I Propose to say a few words about my suggestion that Massey College is the only place at which proper training can be provided. Some years ago the question 
of whether the college should carry on an extension service of this kind, which is in reality a contracting service, was considered by the College Council. The council decided that, in view of the fact that no other body or "individual was providing the type of service given by the College farm drainage service and because of its potential value as a training unit, it should be retained, but that it must be self supporting.

Although I have suggested that it should be used to, train drainage experts, this could be possible only if it were relieved of the cost of such training. It is unfortunate that I should have to advocate the use of our drainage service for training, because somebody is bound to accuse me of being actuated by ulterior motives, I want to assure you that my only concern is that of doing something which I am certain will increase primary production and be of ultimate benefit to New Zealand. I am too near the retiring age to want to burden myself with extra work and responsibility merely for the sake of what is popularly known as empire building. points :-

As a concluding note let me emphasise a few

1. The efficient use of machines for farm drainage is dependent on good planning and organisation.

2. Unless such planning is done and properly surveyed lines_on_which. to_work_are_set_out, _the_use of machines must, except on the most simple and straightforward schemes, lead to poor or costly work.

3. The cost of planning and organisation has been estimated by $\mathrm{Mr}$ Bowler to represent about 30 per cent of the total cost of contract drainage work.

4. Comprehensive planning of a whole farm or a group of farms is most desirable in the majority of cases, even though the work of installing the system must be spread over several years.

5. Income to the extent of $£ 200$ a year spent on new drainage is exempt from income tax.

6. I suggest the Department of Agriculture should lay down 'drainage experiments and demonstrations in Northland with the object of encouraging farm drainage. 


\section{DISCUSSION ON ALL DRAINAGE PAPERS}

Q. Could the soil conservation people be asked by the Association to support such a scheme as that operated by Massey College?

A. (President): It is not advisable to have the Association used as a chopping block. It must be for those in leading positions in catchment boards, etc., to make the approach to those who control the purse strings.

Q. Is there any type of drainage intermediate between the temporary (surface) type and the permanent (tile) system that could be recommended?

A. (Bowler) : A drainage system can be planned only as the result of a contour survey. It is impossible to identify falls on flat country. If you favoured surface drainage you would first have to have it planned for underground drainage.

A. (Banfield): The optimum length of surface drains is not greater than 6 chains if there is a drop both ways. You can have a 'drop of 1 in 50 over 3 chains. Moles therefore would work for a reasonable time. When surface drains are put in by machine the farmer usually does a little touching up with the shovel and the fall is reasonable.

A. (President) : It was customary in England for a long time to combine the type of drainage (surface) described by Mr Banfield with tiles and moles. An area was thrown into lands. It was not necessary to drain the tops of the lands. In the sort of land suitable for surface drainage we do not seem to have the "freeboard" necessary for out'lets to underground drains.

Q. Could the speakers indicate the amount of improvement as a result of some of the drainage work done ?

A. (President) : Farmers have said that with open drains they have lost in one night as many lambs on one paddock as would pay for drainage with tiles and moles-say nearly £20 per acre. Tile drainage is very expensive. I would hazard the suggestion that tiles at $2 \mathrm{ft}$. to $2 \mathrm{ft}$. $6 \mathrm{in}$. or $2 \mathrm{ft}$. 10in. deep might equal $£ 50$ per acre for drainage. Drainage is a long-term investment. A life of 25 years can be assumed: $£ 50$ for 25 years at $4 \frac{1}{\mathbb{1}}$ per cent interest on table mortgage requires $\mathfrak{\$} 3 / 5 /-$ per annum principal and interest, which equals about ' $261 \mathrm{~b}$. of butterfat at $2 / 6$ per lb. If, having spent $£ 3 / 5 /-$, you are unable to increase production from the land by $261 \mathrm{~b}$. of butterfat, obviously drainage is not worth while. There have been cases of increases of 50 to $601 \mathrm{~b}$. of butterfat per acre after installation of drainage.

A. (Banfield): On the [Hauraki Plains in the 4 winters prior to the last, conditions were particularly dry and production as assessed from factory figures went up 40 per cent. Most of this increase could be considered to have been brought about by what is the equivalent of better drainage.

Q. In view of the cost of tile drainage, is mole drainage a satisfactory system as a substitute?

A.. (President) : Where. mole drainage is possible use it by all means. One of the first things Mr Bowler would advocate if he goes on to a farm that can be mole drained is that it should be so drained. It is often a 'matter of combining 
moles with tiles. The Mcleod system is suited mainly to land with good falls, say 1 in 20 to 1 in 60 . Flattish country is not suited to the system. I am afraid there is a tendency to abuse some of these drainage systems, such as, for instance, the spear system. The difficulty is that too great a volume of water is put into the major tiles which are overloaded and scour. The systems need to be cautiously applied. There are Massey College and Department of Agriculture publications available on mole and tile drainage systems.

Q. Could the panel give any information on concrete tiles?

A. (President): They should be perfectly satisfactory if they are well made. Several concerns in both Islands have made them in the past, but all have gone out of the business. I have seen concrete tiles so unsatisfactory that they have disintegrated in 6 weeks. Even those most enthusiastic about the making of concrete tiles were not prepared to go into their proper curing. They must be made with a very dry mix. The key to proper manufacture is steam curing. They could be made by the farmer with simple moulds and laboriously, but it is hardly a practicable method.

Q. Has there been any experience with ditch diggers?

A. (Scott): We are aware that machines of that type are available. Their disadvantage is that they cannot cut to a pre-surveyed grade. On country that hast an obvious and continuous fall they are all right but where a survey and accurate work are necessary they fall down badly. For open ditches they are all right, but who wants open drains? You can lose stock in them that would soon pay for tile drainage. Massey College looked at all types and tried most, and all things considered the ones used by the service at present are the best.

Q. What are the allowable velocities in streams, particularly in North Auckland, on various soil types?

A. (President): Allowable velocities must vary considerably. Scour is not only a matter of velocity, but of volume as well. No doubt if you could get a standard text-book on engineerings aspects of drainage you would get figures for various conditions, but I don't know of any work having been done on the problem.

Q. If drainage is considered a first priority in breaking in land, why in the land we saw yesterday †Puketitoi Block was the need for drainage apparent?

A. (Sinclair): Unfortunately we haven't the answer to the drainage of gumlands on the flat and on slopes. The reason we haven't tackled drainage before grassing is that we don't know how to tackle it, and when a dry summer comes :we find it handy to have occasional wet spots.

A. (President): Because of the limited value of species that would survive in those wet spots I doubt their value up here in August. My suggestion is that the Department of Agriculture should carry out experiments. There are plenty of people in the north who have had experience and it should be drawn on. There is a great variety of soils on some of which mole drainage should be quite effective. There are some on which under drainage of any 
sort " would not be wholly satisfactory. There is an impervious gell through which water will not percolate to under drainage. The great problem is to maintain an even surface that does not form little puddle dams. The answer might be a combination of the Banfield system and under drainage. The land should be thrown into ridges and furrows and tiles laid in the furrows and at intervals little soak pits of scoria or rock sunk. That is roughly the germ of the idea, but until someone tries things systematically we will still be looking for the answer. Very few men have all the answers to all the problems.

Q. Is there any faster machinery than the dragline ?

A. (Scott) : The Lewis drainer, which uses two large discs on a slight angle, would do it quicker, but would not make such a large drain as you want and you might have to do the job again. The Cuthbertson, a Scottish machine, could be used with a large and powerful tractor. The Swamp Buffalo can be used practically on water..

Q. Has the panel any experience of open drains made with the bulldozer?

A. (Bowler): For soils other than heavy soils you would probably do the work cheaper with a road grader. You would need to have all tile drains leading into such drains on the vertical side., as there would be pugging and blocking of outlets of tiles emerging on the sloping grassed area of such a drain.

A. (Banfield): The system has been used a lot in Hauraki both on clay and neat. So far it has been auite satisfactory, but it is too soon to pass judgment.

Q. The outlet system is breaking down on the Ruawai Flats, The main trouble is that insufficient room was left for the road and drains on either side, in addition, telephone and power poles impede cleaning with the dragline. The drains are quite capable of carrying the water away providing the canals can be cleaned.

A. (President) : The answer in Ruawai as on Hauraki lies in pumping to keep outlets clear.

A. (Scott) : The side tractor-mounted version of the machines demonstrated at the field day would be worth trying. It can be fitted with a large bucket and has an extended reach.

Q. Has there been any success in getting rid of rushes with mole drainace?

A. (Banfield): On wetter, Iower slopes you would still have to do more than mole drainage would accomplish. Some farms free of rushes have been finally cleared by constant mowing and spading. 